\title{
A NEW BOLIVIAN TRACHYSPHYRUS OF THE IMPERIALIS GROUP (HYMENOPTERA, ICHNEUMONIDAE)
}

\author{
By Charles C. Porter \\ Museum of Comparative Zoology, Harvard University
}

Entomologically, Bolivia is perhaps the least known part of Latin America. In 1967, when I published a monograph of the nearly Ioo predominantly Andean and southern South American species of Trachysphyrus, I could include only two records from that country, although adjacent Perú, Chile, and Argentina were each found to be major centers of abundance and diversity for Trachysphyrus. In March of 1968, however, when I was able to spend a week collecting near La Paz, I discovered an abundant and conspicuous new Trachysphyrus belonging to the group of $T$. imperialis Haliday, as defined in my earlier study (Porter 1967, p. 275).

\section{Trachysphyrus praeclarus n. sp.}

Figure I

Holotype: (female) bolivia (La Paz: Cota Cota, March 4, i968, A. García \& C. Porter) ('Tucumán). Paratypes: (2 I males) Bolivia (La Paz: Cota Cota, March 4, 1968, A. García \& C. Porter). (Cambridge, Ottawa, Porter, San Francisco, Townes, Tucumán, Washington).

Female: Color: flagellum black with dull brown staining below toward apex and with a white band above on segments 5-9; scape, head, mesosoma, and gaster bright cupreous metallic, especially on head and mesosoma with bronzy-golden reflections; wings dark with brilliant metallic reflections; coxae and trochanters cupreous metallic with trochantelli becoming orange-brown on apex; fore and midfemora bright pale orange with dark cupreous metallic staining below on about basal $1 / 2-2 / 3$; hind-femur bright pale orange with some brown staining on base; tibiae bright pale orange, especially the hind-tibia with a little dusky staining on apex; tarsi mostly black. Length of fore-wing: $10.6 \mathrm{~mm}$. Ist flagellomere: 4.0 as long as deep at apex. Clypeus: low, very weakly convex in profile; apical margin practically truncate. Malar space: I.I as long as basal width of mandible. Temple: 0.8 as long as eye in dorsal view; gently receding. Mesoscutum: notauli sharp, traceable a little less than $\mathrm{I} / 2$ the length of mesoscutum; surface smooth and shining with abundant, predominantly sharp, small to large punctures which are mostly subadjacent 


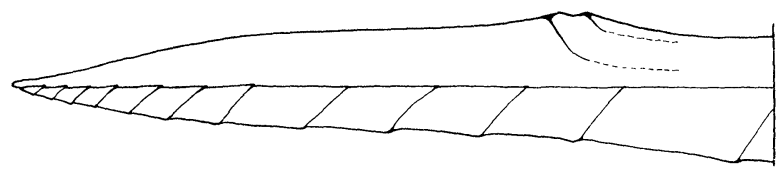

Figure 1. Trachysphyrus praeclarus n. sp. Lateral view of apex of ovipositor.

to in great part irregularly somewhat more widely spaced, becoming largest, densest, and with some tendency to longitudinal slurring on central lobe. Mesopleuron: speculum mostly smooth and polished, surface otherwise with uniform, coarse reticulate wrinkling. Metapleuron: with very coarse reticulate wrinkling. Wing-venation: areolet very large and rather high, intercubiti weakly convergent above to practically parallel, 2nd abscissa of radius I.O-I.2 as long as Ist intercubitus; 2nd recurrent near middle of areolet; discocubitus very gently arched and sometimes slightly sinuate, with or without a stump of a ramellus; nervulus about $1 / 6-1 / 3$ its length postfurcal; nervellus broken a little below middle, upper part about I.I as long as lower. Propodeum: rather short and high, basal face arched and considerably sloping behind, apical face discrete and almost vertically declivous and only about $2 / 3$ as long as basal face; area basalis truncate behind; basal trans-carina definite but a little irregular medially, becoming obsolete laterad of areola and sharp again between spiracle and base; apical trans-carina practically absent except for the rather large, prominently projecting, bluntly cuneate cristae; median longitudinal carinae vague, areola hexagonal and a little wider than long, anteriorly elongate and strongly narrowed; lateral longitudinal carinae vague and irregular, a slight denticle at their juncture with basal trans-carina; surface with coarse reticulate wrinkling that grades basad of basal trans-carina into finer sculpture with some discrete intercalated punctures. Ist gastric segment: postpetiole 1.5 as wide at apex as long from spiracle to apex; dorsal carinae only very faintly suggested for a short distance above and a little in front of spiracle, scarcely defining a median elevation; surface of postpetiole smooth and polished with very faint micro-shagreening and, especially laterally and apically, with rather few, small to tiny, inconspicuous, widely scattered punctures which emit short, well separated setae. 2nd gastric tergite: smooth and highly polished with very fine, weak micro-reticulation and numerous, well spaced, tiny, superficial punctures that emit short setae which largely but not entirely fall short of the length of their interspaces. Gaster: mod- 
erately stout fusiform; succeeding tergites with a little stronger microreticulation and somewhat more abundant setae than on 2nd. Ovipositor: sheathed portion 0.6 as long as fore-wing; gently upcurved; nodus distinct, with a large but rather shallow notch which emits a moderately short, broad, shallow, foreward-directed fossa; dorsal valve in profile gently and directly tapering on about basal $2 / 3$ and then with a more convex taper on apical $1 / 3$; tip 0.24 as high at notch as long from notch to apex.

MALE: differs from female as follows: Color: flagellum solid black, except in many but not all specimens with a white band above on segments I3-I7 to as few as I4-I5; a white line on hind-orbit above; sometimes with blueish reflections, especially on gaster; mesosoma sometimes more extensively golden or greenish-golden than in female; femora and tibiae sometimes a little deeper orange than in female; ventral dark metallic areas of fore and mid-femora averaging broader than in female, occasionally extending nearly throughout and reaching farther laterad or even continuing onto dorsum for a short distance near base; hind-tibia blackish on about apical I/8-I/6 or more behind and somewhat more narrowly so elsewhere; tarsi more intensely black, except hind-tarsus white at least above and often throughout on about apical I/2-3/4 of 3 rd segment and on all or almost all of 4 th segment. Length of fore-wing: $9 . \mathrm{I}-\mathrm{II} .4 \mathrm{~mm}$. Ist flagellomere: 2.9-3.2 as long as deep at apex. Malar space: 0.8-0.9 as long as basal width of mandible. Temple: 0.8-0.9 as long as eye in dorsal view. Mesoscutum: notauli averaging a little longer, traceable about $\mathrm{I} / 2-2 / 3$ the length of mesoscutum; punctures averaging a little denser but mostly sparser than subadjacent. Propodeum: lower and longer in profile; basal face long and rather steeply sloping, apical face considerably shorter and obliquely declivous, merging more or less smoothly with basal face; basal trans-carina as in female or sometimes defined throughout or sometimes practically absent; cristae sometimes a little smaller and lower, bluntly to sharply cuneate; median longitudinal carinae, areola, and lateral longitudinal carinae often vaguer than in female; surface scarcely less coarsely reticulately wrinkled basad of basal trans-carina than elsewhere. Ist gastric segment: postpetiole I.O-I.I as long as wide at apex; dorsal carinae scarcely detectable; surface of postpetiole with more numerous, widely separated, but often more generally and sometimes almost uniformly distributed, moderately small to tiny punctures which emit long and usually at least in part somewhat overlapping setae. 2nd gastric segment: smooth and highly polished, practically without or at least with fainter micro-reticulation than in female and 
with abundant, well separated, small, sharp punctures emitting long setae which in great part exceed the length of their interspaces. Succeeding tergites with stronger micro-reticulation and even more numerous punctures and longer, more extensively overlapping setae.

Collections: The holotype is in the Instituto Miguel Lillo at Tucumán, Argentina. Paratypes have been deposited in the Instituto Lillo; the Museum of Comparative Zoology at Cambridge, Massachusetts; the Canadian National Collection at Ottawa; the collection of Charles C. Porter at Cambridge, Maryland; the California Academy of Sciences at San Francisco; the collection of Henry K. Townes at Ann Arbor, Michigan; and the United States National Museum at Washington, D.C.

Discussion: In its brilliantly metallic ground color, strong but dorsally unmodified epomia, large and nearly parallel-sided areolet, nearly straight 2 nd recurrent, straight mediella, in having the axillus intermediate between the posterior margin of the hind-wing and the submediella, and in its elongate propodeal spiracle praeclarus is a typical representative of the Imperialis Group.

Among those subdivisions of the Imperialis Group proposed in my recent study of the South American Trachysphyrus, the present species fits best in the Metallicus Subgroup, a series previously unreported for Bolivia but known from Andean habitats in Ecuador, Perú, and northern Chile. However, praeclarus differs from my earlier diagnosis of the Metallicus Subgroup (Porter 1967, p. 276) both because it has the notch on the ovipositor tip a little shallower with the accompanying fossa comparatively shorter and weaker, as well as because in the female its propodeum has more strongly projecting and more wedge-shaped cristae and in form is a little shorter and higher than with most of the other species of the subgroup. Nonetheless, these are quite minor differences and there can be no doubt but that this new species belongs to the same radiation as metallicus and its previously described relatives.

Within the Metallicus Subgroup, praeclarus seems especially close to the Peruvian species florezi and aglaus. From florezi it may be distinguished additionally by the following characters: flagellum often banded with white; mesoscutum more uniformly punctate, with punctures of lateral lobes less contrastingly smaller and sparser than those of central lobe; mesopleuron except on speculum uniformly reticulately wrinkled, without a smoother area above along prepectal carina; and propodeal cristae in both sexes more wedge-shaped and more strongly projecting. Moreover, aglaus, which is known only in the male, differs from praeclarus in its more uniformly golden thorax 
and propodeum; dark femora and tibiae; uniformly dark hind-tarsus; more strongly receding temples; the same mesoscutal and mesopleural characters which separate florezi from praeclarus; irregularly shaped areolet with 2nd intercubitus only 0.7 as long as Ist; and shorter and higher propodeum with the apical face nearly vertical and the apical trans-carina distinct throughout.

On the infra-specific level, a striking feature of praeclarus is the inconstancy of its white flagellar band, which, at least in the male, is greatly variable in extent and often may be completely absent, whereas in most other species of Trachysphyrus the presence or absence of a pale antennal band is a stable character.

Finally, although $T$. venustus and $T$. kinbergi are the only species of the Imperialis Group currently reported from Bolivia in addition to $T$. praeclarus, it should be kept in mind not only that most of the other Peruvian and North-Argentine forms may be expected to occur there but also that a region so ecologically diverse and so little explored is practically certain to harbor more new species.

Habitat notes: The type locality, Cota Cota, is situated immediately above $\mathrm{La} \mathrm{Paz}$ at about 4000 meters' elevation but still in a high desert environment rather than in the puna. Here most specimens of praeclarus were collected along a path bordered by a lush growth of large cactus, leguminous shrubs, and many herbaceous plants, the majority of which was in flower. During periods of sunlight many individuals of this species were seen flying swiftly in and around the tangles of vegetation but they would cease activity at once whenever the sun was obscured, even for a moment, by clouds.

Specific Name: Praeclarus is a Latin adjective meaning "splendid" or "illustrious".

Acknowledgements: Praeclarus was obtained during fieldwork made possible by a National Science Foundation Grant, under which the author is Associate Investigator, awarded to Dr. Howard E. Evans of the Museum of Comparative Zoology of Harvard University. I thank also Señor Fadrique Muñoz Reyes and the personnel of the Bolivian Ministry of Agriculture for their generous collaboration during our stay in La Paz. Finally, it gives me pleasure to acknowledge the help of my friend and assistant, Señor Alberto S. García Ferrer of the Universidad Nacional de La Plata (Argentina), who collected a considerable part of the type series, including the unique female.

Porter, C. C.

\section{REFERENCE}

1967. A Revision of the South American Species of Trachysphyrus. Mem. Amer. Ent. Inst. 10. 

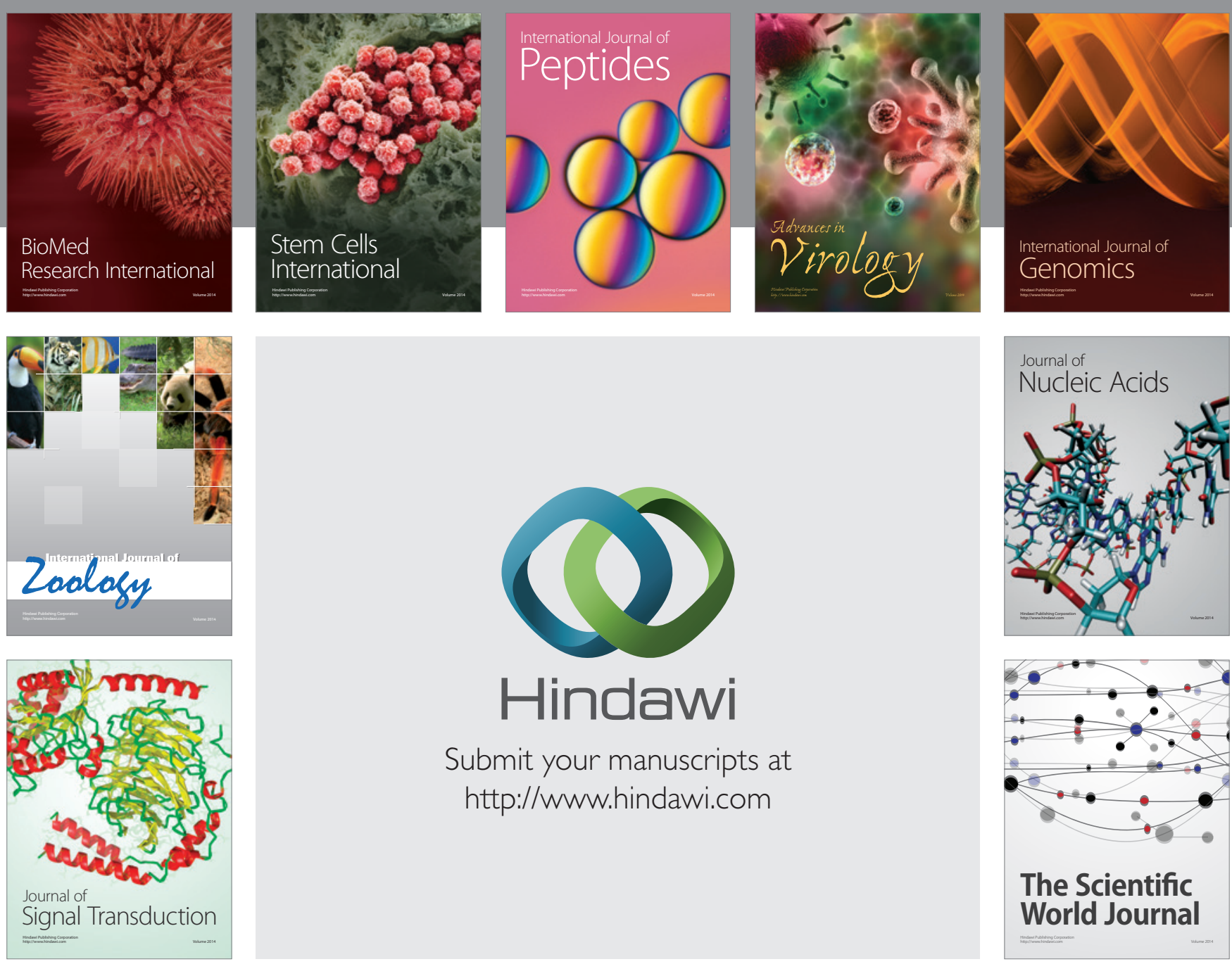

Submit your manuscripts at

http://www.hindawi.com
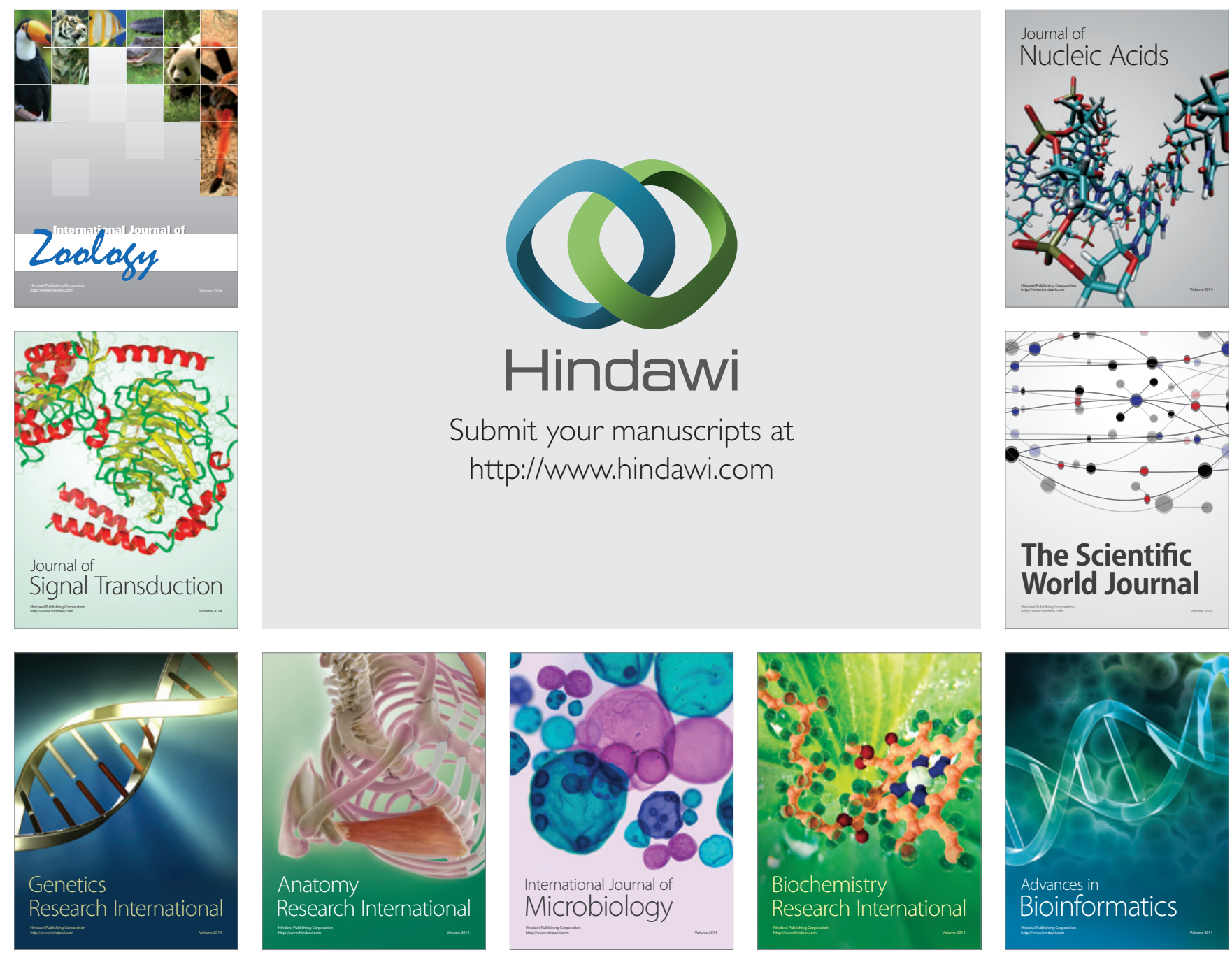

The Scientific World Journal
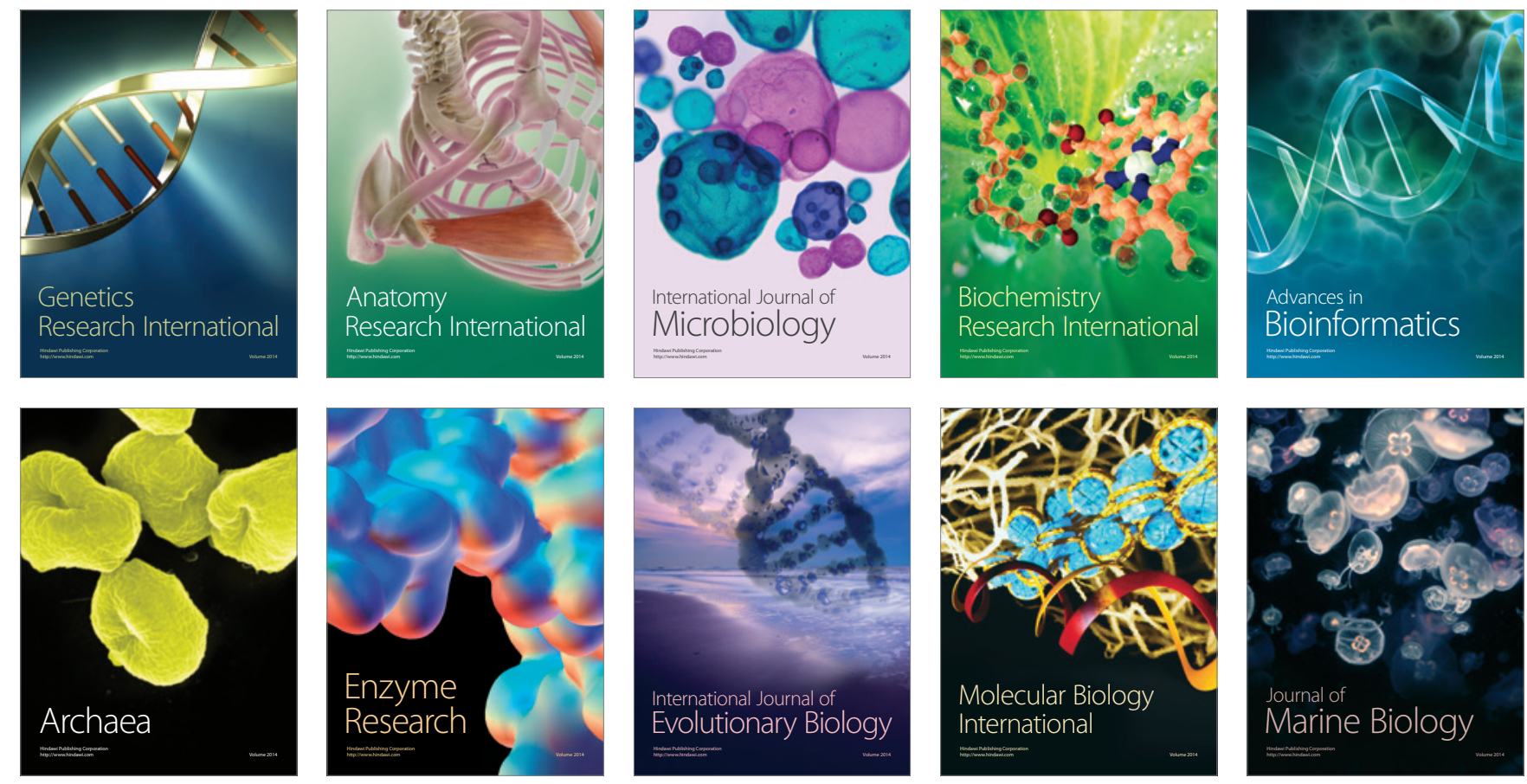